Loading

The Journal of the Canadian Game Studies Association

\title{
"My pockets are full": The Emotional and Mechanical Function of Goodbyes in Animal Crossing
}

Anna Maria Kalinowski

Volume 13, Number 22, 2020

Animal Crossing Special Issue

URI: https://id.erudit.org/iderudit/1075263ar

DOI: https://doi.org/10.7202/1075263ar

See table of contents

Publisher(s)

Canadian Game Studies Association

ISSN

1923-2691 (digital)

Explore this journal

Cite this article

Kalinowski, A. (2020). "My pockets are full”: The Emotional and Mechanical Function of Goodbyes in Animal Crossing. Loading, 13(22), 59-71.

https://doi.org/10.7202/1075263ar

\section{Article abstract}

This article focuses on goodbyes within the Animal Crossing series, describing them as an important but often overlooked mechanic afforded through the inventory space. Beginning with defining the general mechanics withing the series, the article highlights the value of inventory space and argues that inventory space affords the central mechanic of collecting to emerge. As inventory space is not infinite, collecting is accompanied by the necessary mechanic of goodbyes. In order to make more room to collect players will be faced with choices of departing from both items and villagers, the game's NPCs (Non-Playable Characters), emphasizing goodbyes' mechanical and emotional function within this virtual world. Ultimately, this article concludes by highlighting how these mechanics serve to emphasize the parasocial attachments and agency players encounter when faced with the dilemma of departure.
This document is protected by copyright law. Use of the services of Erudit (including reproduction) is subject to its terms and conditions, which can be viewed online.

https://apropos.erudit.org/en/users/policy-on-use 


\title{
"My pockets are full": The Emotional and Mechanical Function of Goodbyes in Animal Crossing
}

\author{
Anna Maria Kalinowski \\ University of Toronto \\ annamaria.kalinowski@mail.utoronto.ca
}

\begin{abstract}
This article focuses on goodbyes within the Animal Crossing series, describing them as an important but often overlooked mechanic afforded by the player's inventory space. Beginning with defining the general mechanics within the series, this article highlights the value of inventory space and argues that it affords the central mechanic of collecting to emerge. As inventory space is not infinite, collecting is accompanied by the necessary mechanic of goodbyes. In order to make more room to collect players will be faced with choices of departing from both items and villagers, the game's NPCs (Non-Playable Characters), emphasizing goodbyes' mechanical and emotional function within this virtual world. While the goodbyes associated with NPC villagers function as emotionally affective examples of goodbyes, they often overshadow the smaller and more frequent goodbyes that emerge in the moment to moment interactions with inanimate objects. These smaller goodbyes which generate minor affections may go unnoticed but propel the game forward and allow for the collecting gameplay to take shape. Goodbyes exist on a scale of affective and mechanical functionality that showcases their diverse structure. It is the goodbyes that we do not notice that most significantly propel Animal Crossing forward and that are always in conversation with the spatial affordances and collecting mechanics of the game.
\end{abstract}

\section{Author Keywords}

Animal Crossing; affordances; inventory space; collecting; goodbyes; parasocial relationships

\section{Introduction}

When I think of my time spent in Little Moon, my fictional town within Animal Crossing: New Leaf (Nintendo, 2012), my mind immediately wanders to a memory regarding my favourite villager Anchovy. Anchovy, the little bird identified by his lazy personality and bold eyebrows, was part of my game from the first virtual day. At one point in my New Leaf journey, Anchovy approached me and brought up the possibility of moving away. Move Away, Anchovy? And leave me? As my first Animal Crossing game and therefore my first experience with a villager's potential departure, this moment was not only a personally memorable gaming encounter, but also the first instance during which I was faced with one of Animal Crossing's central mechanics: goodbyes.

Goodbyes within Animal Crossing can be interpreted in several ways. For instance, players may bid farewell to hours of their leisure time. As this game can be particularly enticing, suddenly 10 hours of a single day can be easily lost to the act of virtual bug catching. Yet, this is just one type 
of goodbye that a player engages with. Animal Crossing's goodbyes, whether micro or macro in scale of importance or impact, are a central gameplay mechanic. This mechanic functions alongside and may be overshadowed by the other primary mechanic of collecting. Together, collecting and goodbyes emerge from the intricate negotiation of one of the series' primary affordances, inventory space. Inventory space creates the impetus to collect, to fill up empty slots and real estate, but also warns that the acquiring and purging of items will be a necessary action due to the obvious limitations of space, emphasizing the often-overlooked importance of goodbyes. These goodbyes are a mechanical function but also exist on a scale of affective resonance (see Figure 1). There is a recognizable emotional distinction between saying goodbye to a villager and simply discarding an item. That being said, while the affective weight may vary, both acts emerge from the design patterns of balancing collecting with limitations of space and coexist on an emotional scale. Indifference is still an emotional response and thus such a reaction to the temporary separation from an object still functions as a goodbye and serves just as much of a purpose. The structure of feeling attached to goodbyes is always fluctuating, and yet any minor feeling towards a goodbye is an important response afforded by the design of the game and plays a functional role in progressing through the game.

Drawing upon theories of affect and design within game studies, alongside a close reading of Animal Crossing: New Horizons (Nintendo, 2020), this article seeks to capture how goodbyes should be viewed as fundamental mechanic in the Animal Crossing series. The range of affective responses and attachments that are produced from a design pattern may vary on the scale of perceived importance, and yet just like in real life, the degree to which the goodbyes emotionally affect individuals does not understate their presence. In order to capture how goodbyes emerge as a central mechanic, I will first illustrate how the game is structured around the affordances of inventory space that encourages a collector's mentality in the player. From this point, I will highlight how goodbyes are necessary for the gameplay loop of collecting on a purely mechanical level as there are often limitations placed on space and inventory. Following this, I will be focusing on the differences of goodbyes, from the seemingly insignificant temporary farewells to objects, to the emotionally moving goodbyes experienced with villagers, by discussing the constructions of parasocial attachments. Despite this, all goodbyes are important in structuring the mechanical functionality and experience of Animal Crossing, and the minor goodbyes play just as important, albeit more affectively subtle, a role in the game. Not only do goodbyes push the functionality of collecting on a purely mechanical level, but the scale of affective resonance that they exit on highlights the diversity of the mechanic and captures how Animal Crossing ultimately becomes a game of negotiation with goodbyes. 
61 Loading... The Journal of the Canadian Game Studies Association

Vol 13(22): 59-71

http://loading.gamestudies.ca

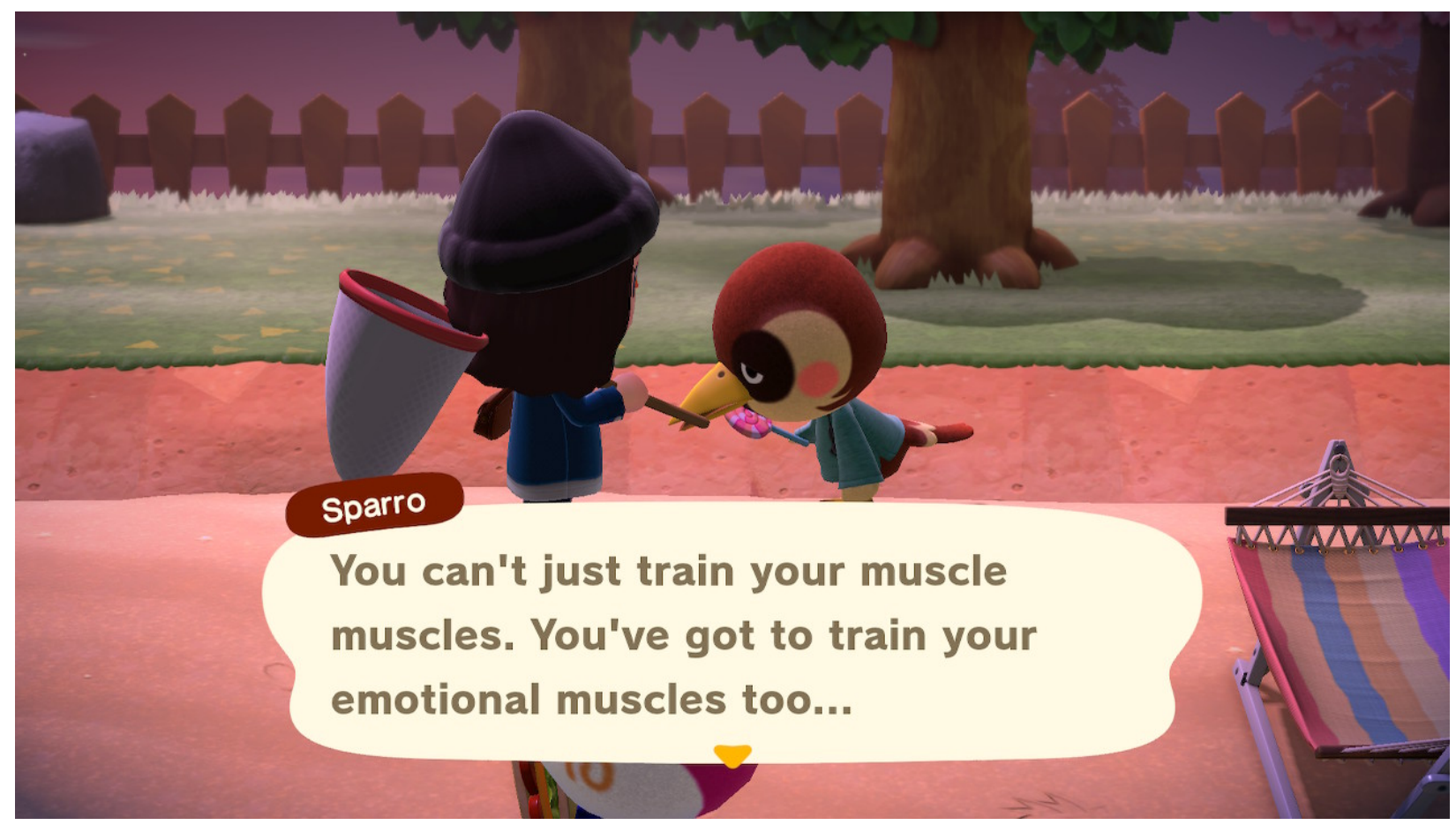

Figure 1. A villager's metaphorically highlighting both mechanical and emotional functionality

\section{Defining a Goodbye}

Goodbyes can have many meanings, functions and interpretations. In many ways, by the time one says goodbye, the inevitability for the separation is already there. There is an arrival of a goodbye as by the time it arrives the goodbye is already set in motion, like a ripple effect of dropping a pebble into still water. When the utterance of a goodbye leaves our lips, there is an understood notion that one has seemingly made up their mind regarding the signaling of the supposed end. However, it is not an innate responsive phrase and rather the perfect goodbye can be viewed as an art form of sorts. How does one say goodbye at the right moment? How does one decide when to go onto the road where goodbye is the final destination? What comes after the goodbye? Some goodbyes are irrefutably surprising, while others are brought upon ourselves or instigated to surprise others. Such brief reflections surrounding goodbyes only skim the surface of how many implications the word elicits, or how the notion of a goodbye manifests itself through multiple terms and phrases.

Dresser and Wasserman (2011) highlight the different ways a goodbye can manifest. As they write, "saying goodbye is familiar; you practice it daily: a kiss goodnight, a 'have a good day' at the end of a phone call, a farewell when you leave someone's home or a party" (p. 63). A goodbye is not simply the moment when the specific word is uttered, and for this reason goodbyes "defy ordinary semantic analysis because they lack literal meaning" (Clark and French, 1981, p. 1). However, while the lack of meaning emerges from the multiple terms, phrases, and frequency with which goodbyes are tossed around, the frequency of the term also reflects its importance and emphasizes the cyclical nature of the goodbye. 'Goodbye' is often associated with routine as the casual semantic bye-bye "is one of the earliest conventionalized 
62 Loading... The Journal of the Canadian Game Studies Association

Vol 13(22): 59-71

http://loading.gamestudies.ca

communicative acts insisted upon by adults and produced by infants" (Greif and Gleason,1980, p. 160), which not only suggests a certain repeatability but a degree of necessity or reliance as well.

These three elements, repeatability, necessity and reliance, play heavily into the functionality of goodbyes within Animal Crossing. Goodbyes come with repeated frequency, they free up necessary inventory space and thus players become reliant on them without even being aware of it. Despite the intricacies of goodbyes, for the purpose of relating them to Animal Crossing it is most convenient to understand goodbyes as the sentiment of separation (Shishikura, 2017, p.232) (see Figure 2). The goodbye is not just a moment where that specific word is uttered, but rather it is a general act of separation that is afforded through Animal Crossing's inventory space. Most importantly though, these goodbyes are not forced, but rather afforded as choices to the player and exist on a scale of meaningfulness.

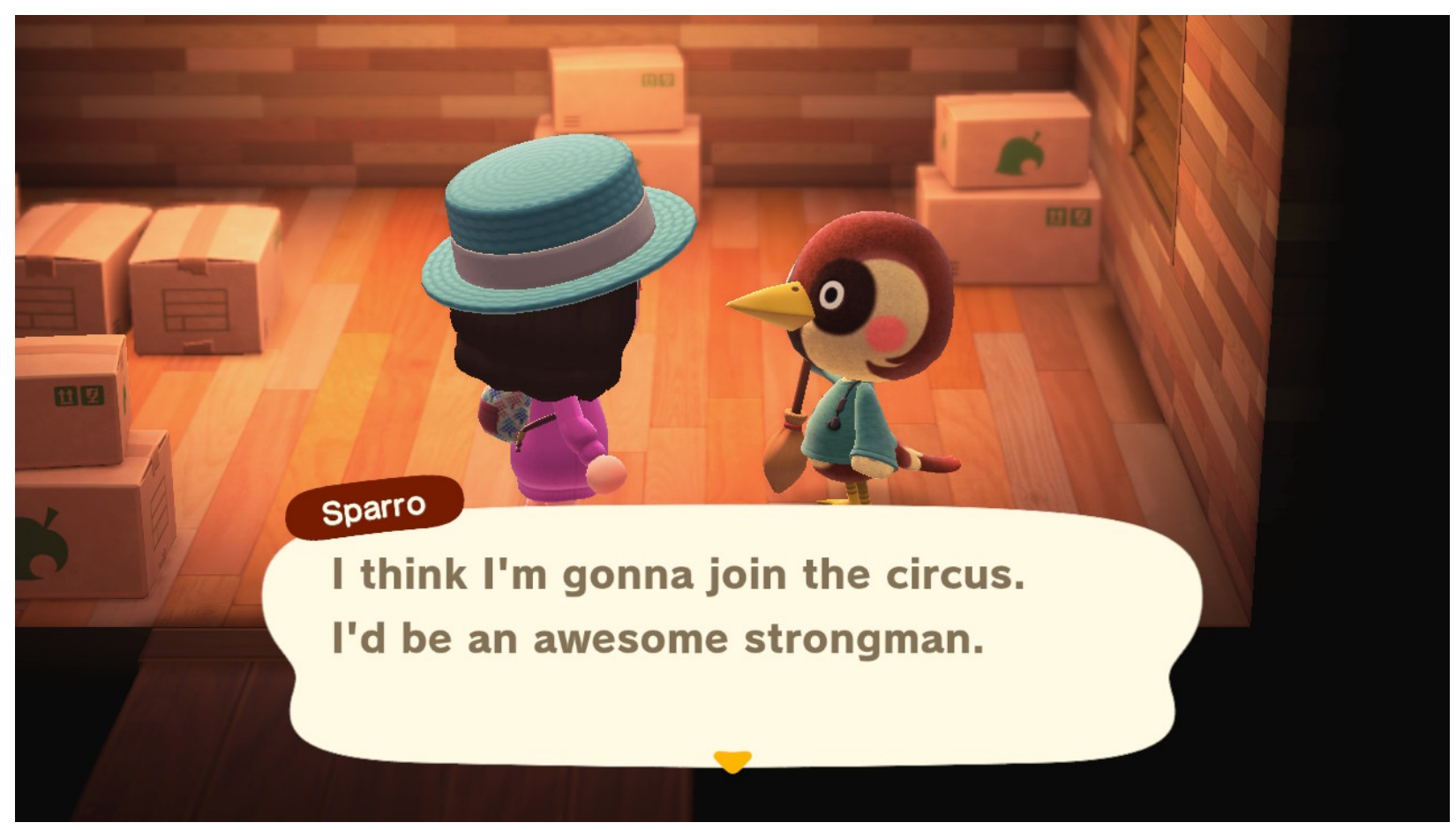

Figure 2. A villager packing up his belongings while saying goodbye to player

\section{Defining the Mechanics of Animal Crossing}

It is quite difficult to pinpoint the central mechanic within the Animal Crossing series.

Perspectives surrounding the series' mechanics substantially rely on the individual journeys that players choose to focus on, whether it be landscape customization (Liffreing, 2020) or multiplayer connections (Kim, 2014). Ian Bogost (2008) describes the title as a sandbox style game which simulates small town social dynamics. While an emphasis of Bogost's perspective is on the economic demands associated with personal wealth and material ownership, he also states that "[Animal Crossing] is a game about customizing and caring for an environment. It is a game about making friends and about collecting insects" (p. 119). This element of collecting is a major point of what supports the gameplay of Animal Crossing. 
63 Loading... The Journal of the Canadian Game Studies Association

Vol 13(22): 59-71

http://loading.gamestudies.ca

Although Animal Crossing may be described as "an infinite game for the purpose of continuing the play" (Carse, 1986, p. 3) with no definitive endings, when speedrunner Coldeggman was recorded to have "completed" the original Animal Crossing game on the Nintendo GameCube in record time, the claims of awarded success were associated with him "collecting every item; finding all fish, fossils, bugs and gyroids; upgrading [his] entire house and Tom Nook's store; donating every possible item to the museum; collecting all villager statues; and building the town's extra bridge" (Frank, 2017, para. 2). Therefore, among the moments of socializing with villagers, expanding interiors of homes, or managing the resulting debts, collecting can be considered as the facilitator to these other mechanics and perceived as the central mechanic within the series.

Collecting effects multiple avenues of gameplay. There is emphasis placed on collecting fruits that fall off trees or shells that wash up on shore to exchange for bells, the in-game currency. In order for the player to expand and furnish their house and pay off debt, the player must initially collect things around the town to sell in exchange for bells. A level of social interaction with villagers is reliant on collecting as well, given that the gameplay involves finding a random item on the ground and searching for the owner of that item, or simply gifting villagers with certain items that the player has collected over time. Interactions with villagers would be limited without the mechanic of collecting. The mechanic of collecting is most clearly emphasized through the museum that appears within every game (see Figure 3), which encourages players to donate each unique bug, fish, fossil or sea creature they find and have a record of their collection. However, the affordance of inventory space is also a foundational element which precedes collecting and encourages collecting to take shape as a mechanic.

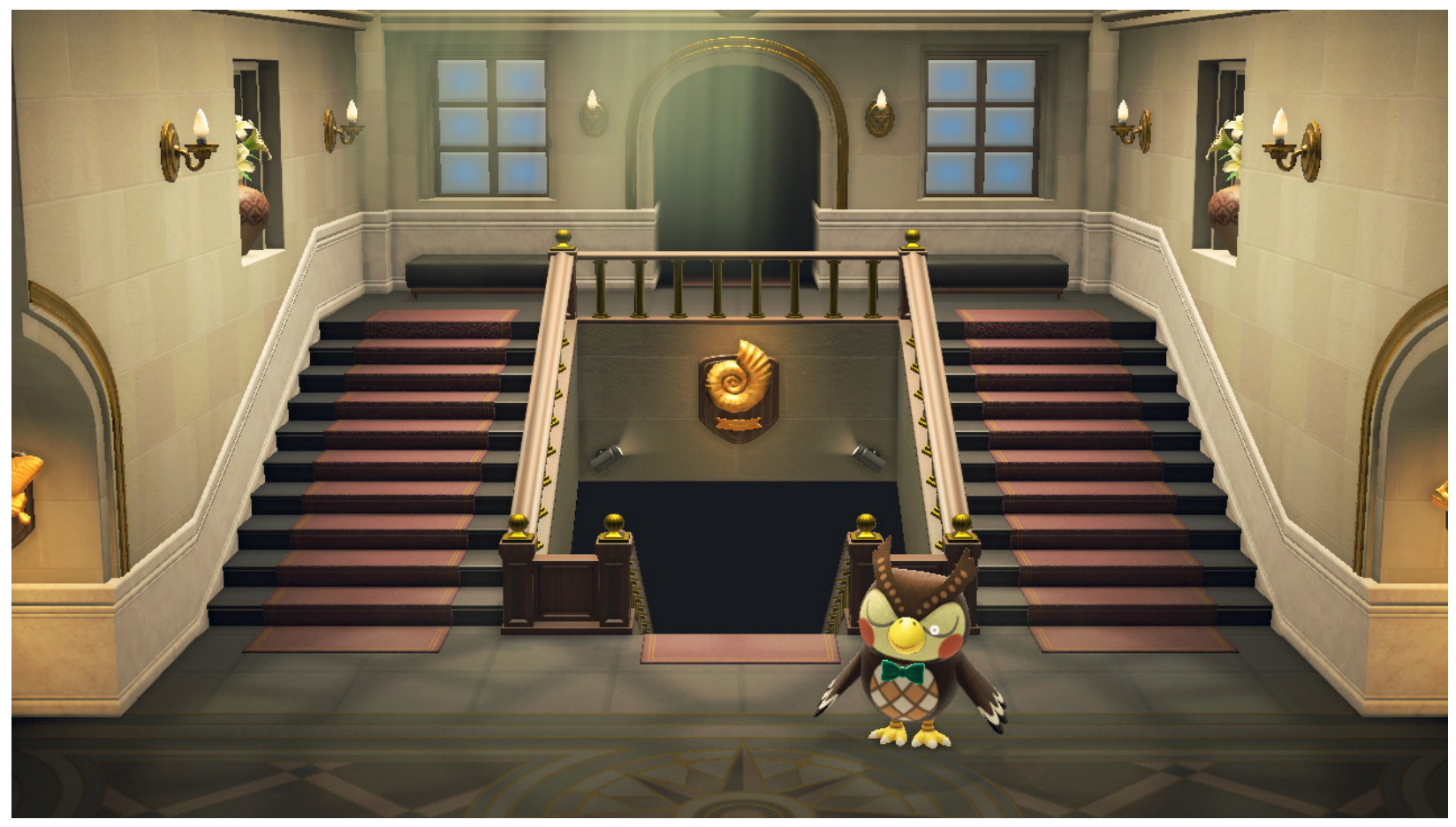

Figure 3. Museum that houses a player's fossils, fish, bugs and art collections 
The term affordance was first coined by James J Gibson (1966) and is described as follows: "[t]he affordances of the environment are what it offers the animal, what it provides or furnishes, either for good or ill... It implies the complementarity of the animal and the environment" (p. 127). Affordances can be more broadly recognized as the "relations between the abilities of organisms and features of the environment" (Chemero, 2010, p. 186), but in the case of Animal Crossing, the affordances simulate the relationship between the players and not a natural environment, but rather a virtual environment.

Within game design theory, affordances are "linked to an opportunity for action; to afford an action is to facilitate or enable it" (Cardona-Rivera \& Young, 2013, p. 1). This conceptualization derives from Don Norman's investigation of affordances in The Design of Everyday Things (1988). Norman's perspective on affordances, in relation to design theories, has established a foundational definition of affordances as he writes:

the perceived and actual properties of the thing, primarily those fundamental properties that determine just how the thing could possibly be used... Affordances provide strong clues to the operations of things. Plates are for pushing. Knobs are for turning. Slots are for inserting things into. Balls are for throwing or bouncing. When affordances are taken advantage of, the user knows what to do just by looking. (p. 9)

This description of perceived affordances may elicit the image of items in Animal Crossing that replicate real life, or virtual environmental affordances that would elicit real world parallels. For example, a watering can within Animal Crossing would afford the action of being picked up by the available handle and watering the surrounding plants; however, this affordance relies heavily on real life associations of what watering cans are used for. A more appropriate example of affordances within the virtual Animal Crossing world would be a bridge that takes structure over the bodies of water and allows for players to traverse the landscape. The knowledge to navigate across bodies of water via bridges aligns with real life understandings regarding the function of bridges. However, the function of a bridge is intuitive in a way that the function of a watering can might not initially be. If the rectangular shape connected two separate islands and looked to carry the weight and size of the player and villagers, then granting the ability to cross over water is its primary affordance. In this same perspective, inventory space functions as a key affordance within the Animal Crossing series. Although the perceived affordances of inventory space are not as straight forward as a supposed bridge, inventory space clearly communicates to the player what needs to occur in conjunction with said space and generates the mechanics that clearly capture how one is to interact with the game.

One of the potentially stressful instances in the generally relaxing series of Animal Crossing is the element of inventory management which impedes on the potential hoarding mentality that may be facilitated by collecting. The inventory of the series is contained in three main distinctive spaces that the player can interact with for the sake of collecting, while simultaneously limiting the amount of things that can be collected: the space in the player's "pocket" which is the inventory that is always carried around on the playable character, the physical space in and outside of the player's house where the player may display things, and the inventory space within the storage units such as dressers within the player's home. These three options are the central inventories that players will most frequently manage.

Another management of potential inventory space is associated with villagers. There is still a sort of systematic management that may occur if players want to "collect" or meet specific villagers 
within their town. This is enforced through the game's limited housing system that only allows for a certain number of villagers to occupy the town at any given time, and furthermore, it is reflected through the online communities formed around strategic trading of certain villagers (Animal Crossing Community, 2020). The collecting of villagers has also transformed the ways New Horizon's Nook Miles ticket function, as they have become a valuable in game and out of game currency (Kent, 2020). Nook Miles tickets are rewarded for completing certain tasks or reaching certain milestones in the game, and can be used in exchange for particular items or, more regularly, to go on a Mystery Island Tour. The mystery island tour is one of the more common ways to meet to random villagers outside of the ones currently inhabiting the player's island, and therefore individuals seeking to find certain villagers often require multiple trips and many Nook Miles Tickets to locate their ideal villager. This has created an intensive demand for Nook Miles tickets and the resulting ticket economy captures the role of villagers alongside the collecting mentality within the game.

This mechanic of collecting is central to the series and is generated through the affordances of inventory space. If there is empty space, collecting things will fill it and therefore the game is encouraging that it should be done (see Figure 4). However, there will certainly be moments in the Animal Crossing series when a player attempts to pick up an object and realizes their pocket is full (see Figure 5). In this instance, players are given the option to drop an item to make space for their newly acquired finding. The same aspect applies to the limited house space. Players needs space to store things in their home or outside of their home, and if there are too many things that take up that space then things must be either stored in dressers (until that inventory is filled) or players must get rid of said items. Inventory management is not just a case of rearranging items, because players will always be faced with the dilemma of getting rid of certain things in order to have the chance to manage new things and, in a sense, collect more to further engage with the mechanics of the game. It is a very simple loop that is afforded through inventory space; if there is space then one should fill it, yet, if there is not enough space then there is another important step one must fulfil. A player will frequently be faced with decisions of what to say goodbye to and when those goodbyes should occur. The goodbyes emerge as a necessity from the collector's mentality that is encouraged by the game, and these goodbyes exist on a scale of emotional impact. Some goodbyes are tied to much easier decisions: a weed taking up space in a player's pocket will not be that heartfelt of a separation, but a goodbye to villagers may be more sentimental. By recognizing the range of goodbyes, the mechanic establishes itself with enough diversity to provide intricate interactions to Animal Crossing, whether purely on a mechanical level or on an affective one. By sometimes coming to the surface, or often times functioning in the background, goodbyes are interwoven into the gameplay loop and serve a vital function in the Animal Crossing series. 
66 Loading... The Journal of the Canadian Game Studies Association Vol 13(22): 59-71

http://loading.gamestudies.ca

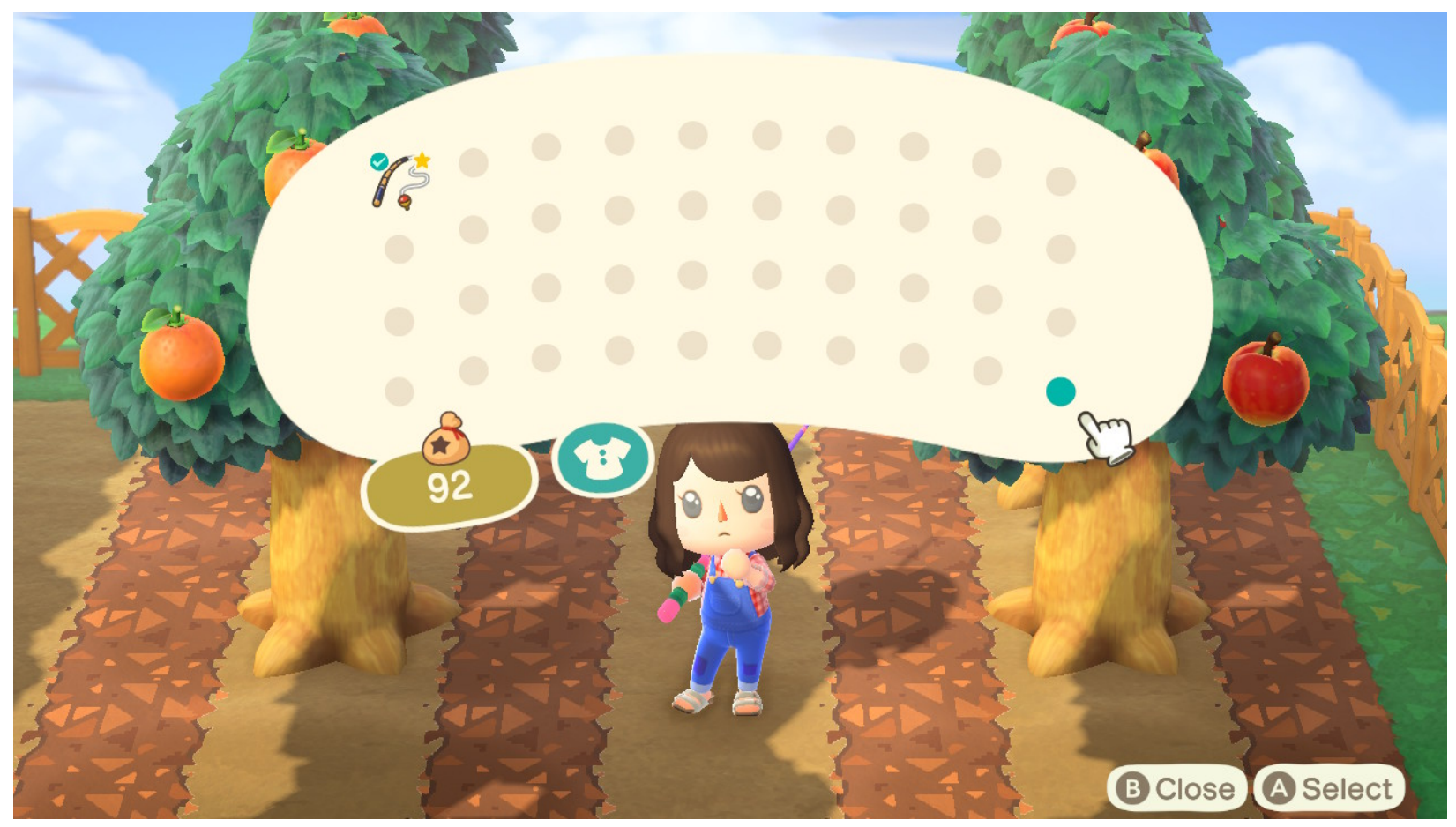

Figure 4. Free spaces of pocket inventory

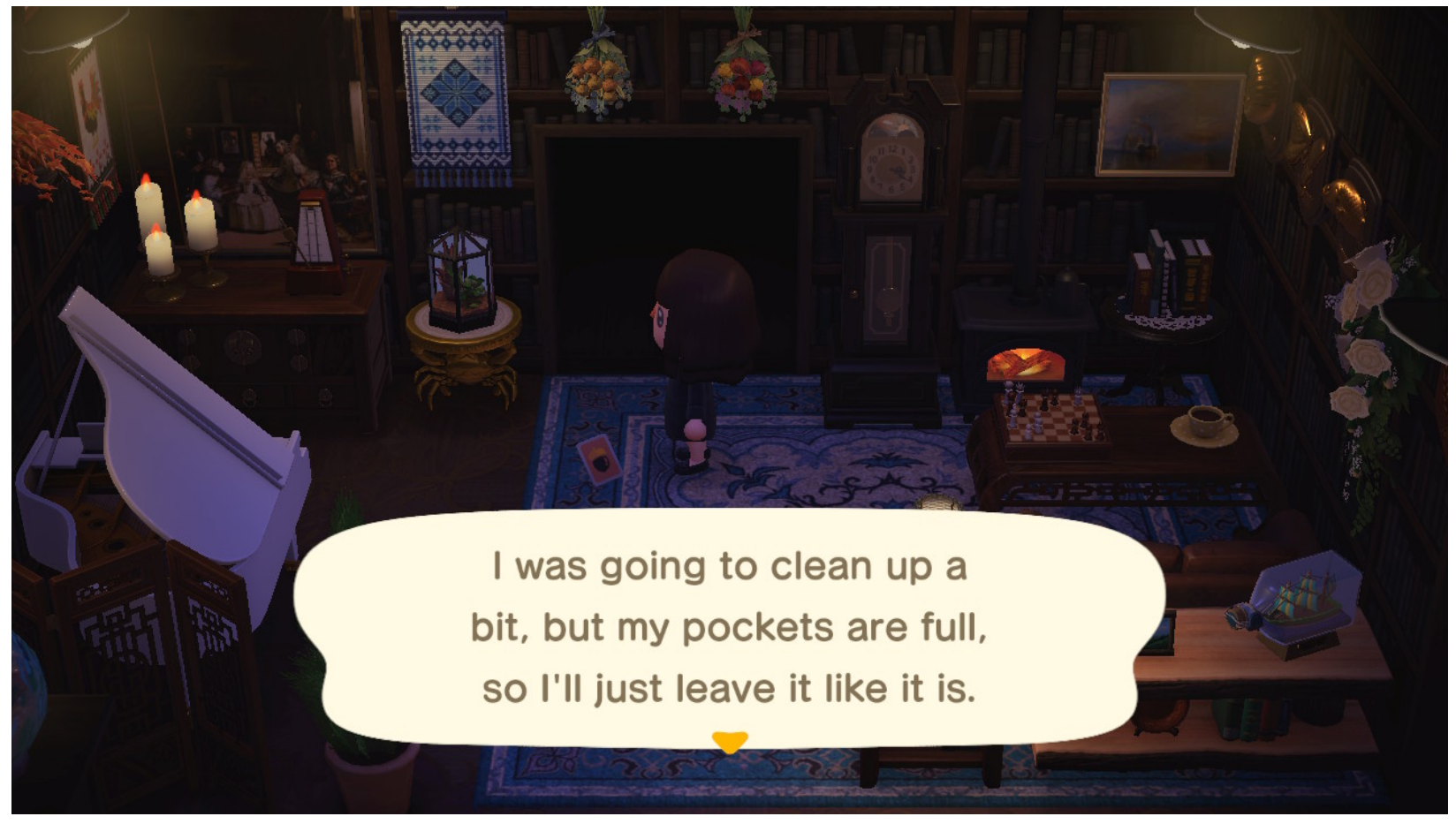

Figure 5. Text notification of full pocket inventory 
67 Loading... The Journal of the Canadian Game Studies Association

Vol 13(22): 59-71

http://loading.gamestudies.ca

\section{The Importance of Goodbyes}

Goodbyes accompany the act of collecting by allowing players to depart from their attachments, whether those attachments are more physical or emotional in nature. Saying goodbye to certain bugs, fish, furniture or even villagers is necessary in order to allow for the gameplay experience to proceed onward. The player could certainly play the game without letting villagers leave, but progression through the gameplay loop would be impossible without parting with objects or catchable critters. The structures of both spatial affordances and limitations necessitate goodbyes. Quite simply, there would be no collecting without goodbyes.

The intertwining of collecting and goodbyes informs Mateas' (2001) approach to affordances as correlated to agency. Agency, he describes, is "the feeling of empowerment that comes from being able to take actions in the world whose effects relate to the player's intention...the effect must relate to the player's intention" (p. 142). This agency afforded via inventory space emerges due to the fact that both the act of collecting and goodbyes within Animal Crossing occur on the player's terms. The players choose what to pick up and what to say goodbye to. That being said, goodbyes, in particular, amplify the range of affective dynamics that come into play alongside the agency associated with choice. This diverse affective resonance of goodbyes cements the act of departure as a very important mechanic that is deeply engrained into the way Animal Crossing is played.

Goodbyes, in a way, emphasize Murray's (1997) take on agency as "the satisfying power to take meaningful action and see the results of our decisions and choices" (p. 126). Jesper Juul writes of how the ability to exchange gifts in Animal Crossing allows players to enact socially meaningful actions (Juul, 2009, p. 124), but I consider meaningful actions to manifest in multiple ways and to different affective degrees. At the surface level, meaningful agency may be immediately tied to the parasocial attachments that are created alongside the anthropomorphic animal villagers. The concept of parasocial was first coined by Donald Horton and Richard Wohl to describe the one-sided connection audiences had with subjects of mass media and a "seeming face-to-face relationship between spectator and performer" (1956, p. 215). These parasocial bonds are often associated with the attachment one feels to fictional characters which is most noticeable with the emotional reaction one has when their favourite show goes off air (Cohen and Eyal, 2006, p. 502). There is a sense of loss during such an occurrence which is perhaps not on the same level of as a separation between two individuals in 'real' life, but nevertheless impactful within our understanding of human connection (p. 504). The parasocial attachments are indeed highlighted through the acts of collecting just as much as they are captured within the moments of goodbyes. The collecting of villagers, as previously captured by the Nook Miles economy emerging from the search that players set out on to locate their favourite villagers, shows the parasocial attachment that players have with the virtual creatures and how meaningful actions are carried out in order to collect them or when the time comes to say goodbye (see Figure . However, I believe that the perception of meaningful agency goes beyond the actions associated with villagers, or even the social exchange of gifts that Juul highlights. While these parasocial attachments highlight one way that goodbyes become recognizable in Animal Crossing, these perceptions of meaningfulness perhaps overshadow the larger functionality and prevalence of goodbyes in Animal Crossing.

Popular media outlets and online forums capture just how affecting goodbyes with villagers can be (Wan, 2020). However, actions and goodbyes do not necessarily need to be extraordinarily 
affectively moving in order to be meaningful. In her discussions of game generated affect, Aubrey Anable (2018) states that games are "a medium that seems to traffic more interestingly in the minor affects" (Anable, 2018, p. viii). While major affections surrounding villagers may be the instances which most significantly highlight goodbyes, it is through the generation of minor affections that goodbyes often go unnoticed and, as a result, contribute the most functionality to the mechanic. It is simple to say that games function as interactive products that solicit emotions through actions (Lazzaro, 2009, p. 156). Emotions direct the efforts and attention of players, and more importantly, aid in the decision-making processes in games (p. 158). In some ways, this may suggest that the solicited emotions must always be significant in order to create such a result. When considering Animal Crossing, the decisions that emerge in-game are often a negotiation between what is important enough to be collected, or what is disposable enough to be subjected to a goodbye. I use goodbye in this instance because of the emotional range that goodbyes inhabit. For example, a goodbye to a loved one prior to a long separation or the goodbye in the midst of a quick phone call with an individual who says they will call right back carry different emotional weights but they similarly signify a separation. The affective range is recognizable but does not erase the presence or function of either goodbye. In fact, the seeming insignificance of the minor goodbyes in Animal Crossing are essential for structuring the gameplay experience. Indifference towards an item or a villager is welcomed in the game as it motivates a different set of actions. Not every encounter needs to be extraordinary affective.

To some extent, Raymond Williams' (1961/2014) concept, structures of feeling, encapsulates the functionality of Animal Crossing's goodbyes. While the concept has been appropriately critiqued for its convenient flexibility (Zembylas, 2002, p. 190) and simply questioned for what it exactly means, it is generative in discussing structure and feeling as entangled, relational and shifting terms rather than existing in a fixed binary (Engle \& Wong, 2018, p. 6). The contradictory words the concept integrates helps illustrate how the affective range of goodbyes serve a purpose. On one hand, there is a structural importance to the goodbyes that serves a mechanical functionality. A goodbye is commonly used as signal for a departure, and can structure conversation and the surrounding actions on a purely functional level. And yet, even while creating this structure, goodbyes have the potential to elicit deep emotions, a potential that does not always need to be reached. The diverse affective value, or lack thereof, allows goodbyes to become an important and diverse mechanic in Animal Crossing. Indifference towards a goodbye engrains the mechanic into a gameplay loop that oftentime goes unnoticed. The parasocial attachment attributed to the villagers of Animal Crossing, and the potential goodbyes players share with them, may highlight the emergence of goodbyes in this one specific aspect of the game and conceal its importance and resonance in other venues. The departure with an item is not nearly as impactful. There may be a sort of 'parasocial attachment' to a fish that is caught that must then be thrown back into the ocean when the pocket is full, but again, it is not on the same level as the separation with a villager. However, this only emphasizes the nuances of how goodbyes function as a mechanic that can go unnoticed and exist alongside more minor affections. It is the goodbyes that we do not notice that most significantly propel Animal Crossing forward and that are always in conversation with the spatial affordances and collecting mechanics the game.

\section{Conclusion}


The importance of goodbyes is frequently overlooked within Animal Crossing and, to a certain degree, that is a sentiment of how seamlessly goodbyes are integrated within the gameplay experience. It is through inventory space that not only the important mechanic of collecting is afforded but that goodbyes emerge as a central mechanic within the series. Space encourages collecting and yet it is limited, therefore goodbyes support collecting by allowing players to separate with objects in order to create opportunities for even more things to be collected. Goodbyes, however, may be most recognizable when the player is faced with the decision to separate from Animal Crossing's anthropomorphic animal villagers. The parasocial attachments developed towards the villagers appear to be the most poignant, whether in the desire to 'collect' certain villagers or being faced with the difficult decision of saying goodbye to villagers that the player has grown attached to. Yet, these significant affective moments of separation from villagers overshadow the more minor affections that are interwoven into the gameplay. A quick goodbye to an inanimate shell that has initially been collected and afterwards is taking up necessary pocket space may seem insignificant, but the lack of emotional gravitas it contributes is valuable in its own right. These minor goodbyes are what drive the gameplay of Animal Crossing forward and allow actions of collecting to function. 'Farewell' (see Figure 6), one of the songs sung by K.K. Slider, the canine musician that visit players in the game, provides an appropriate parallel the how goodbyes exist both on a mechanical and emotional level. The song has a melancholic tone to it that may even be may be described as sad. Listening to the song, just like some experiences with goodbyes, has the potential to consume one with emotions. However, just like many instances of goodbyes, the song can exist in the background without much awareness brought to it. Goodbyes may not always be the most recognizable mechanic, they may exist without notice in the same way that 'Farewell' fills up a room, but in either case it does not undervalue its presence and potential for emotional impact.

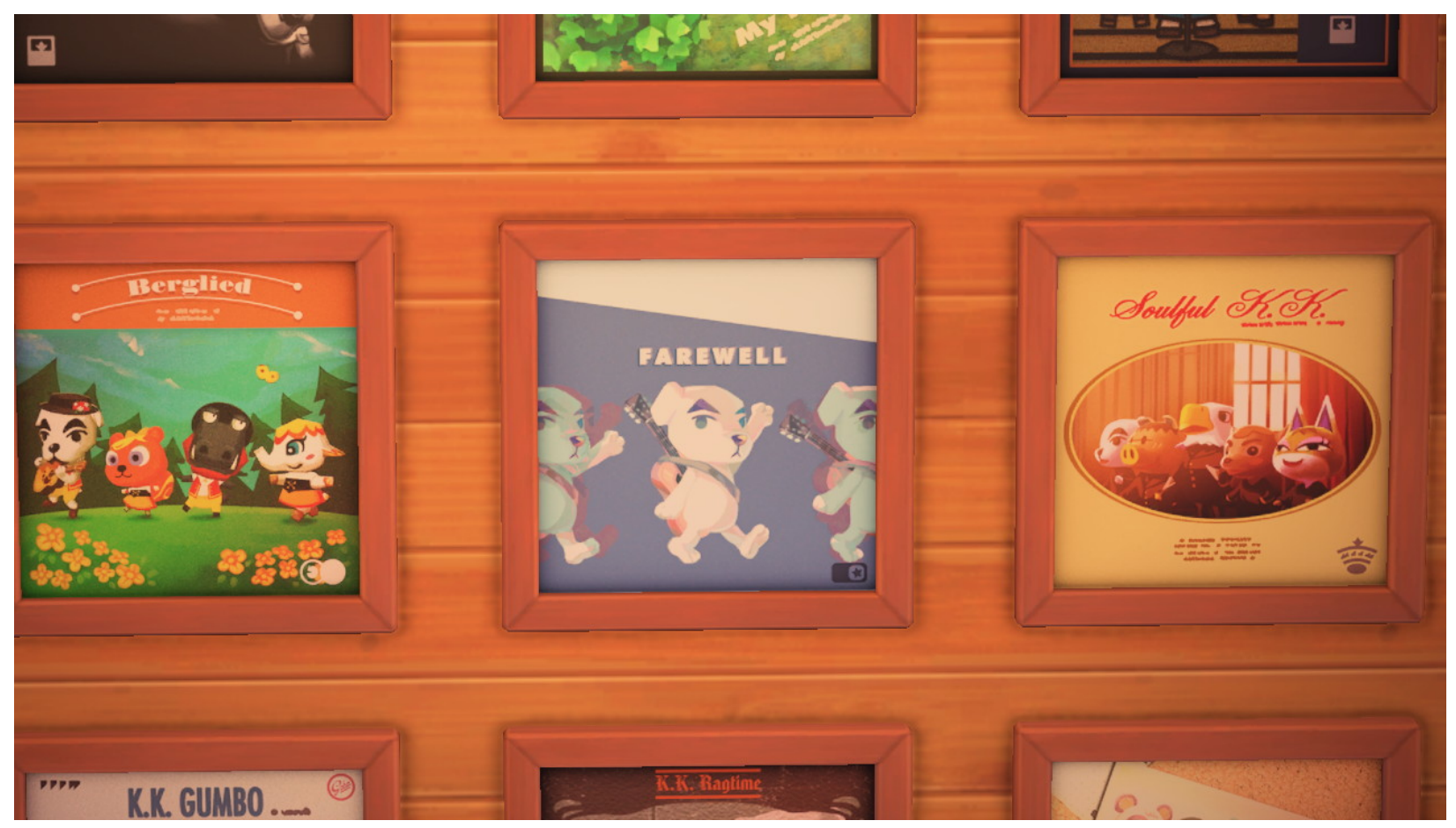

Figure 6. Album cover for K.K. Slider's 'Farewell' 
70 Loading... The Journal of the Canadian Game Studies Association

Vol 13(22): 59-71

http://loading.gamestudies.ca

\section{References}

Anable, A. (2018). Playing with feelings: video games and affect. Minneapolis: University of Minnesota Press.

AC:NL Villager Trading Board. (n.d.). Animal Crossing Community. Retrieved January 7, 2020, from http://www.animalcrossingcommunity.com/boards.asp?BoardID=306

Bogost, I. (2008). The rhetoric of video games. In K. Salen (Ed.), The ecology of games: connecting youth, games, and learning (pp. 117-140). Cambridge, MA: The MIT Press.

Cardona-Rivera, R. E., \& Young, R. M. (2014). A cognitivist theory of affordances for games. Proceedings of the 2013 DiGRA International Conference: DeFragging Game Studies. Presented at the DiGRA Conference.

Carse, J. P. (1986). Finite and infinite games. New York, NY: Free Press.

Chemero, A. (2003). An outline of a theory of affordances. Ecological Psychology, 15(2), $181-195$.

Clark, H. H., \& French, J. W. (1981). Telephone goodbyes. Language in Society, 10(1), 1-19.

Cohen, J., \& Eyal, K. (2006). When good friends say goodbye: A parasocial breakup study. Journal of Broadcasting \& Electronic Media, 50(3), 502-523.

Deterding, S. (2011). Situated motivational affordances of game elements: A conceptual model. CHI 2011. Presented at the ACM CHI Conference on Human Factors in Computing Systems, Vancouver, BC, Canada.

Dresser, N., \& Wasserman, F. (2010). Saying goodbye to someone you love. New York, NY: Demos Medical Publishing.

Engle, K., \& Wong, Y.-S. (2018). Feelings of structure: explorations in affect. McGill-Queen's University Press.

Frank, A. (2017). Animal Crossing speedrunner completes entire game in less than one day. Polygon. Retrieved from https://www.polygon.com/2017/4/24/15407182/animal crossing-speedrun-100-percent.

Gibson, J. J. (1966). The senses considered as perceptual systems. Oxford, England: Houghton Mifflin.

Gibson, J. J. (1979). The ecological approach to visual perception. Boston, MA: Houghton Mifflin.

Greif, E. B., \& Gleason, J. B. (1990). Hi, thanks, and goodbye: More routine information. Language in Society, 300(6722).

Horton, D., \& Wohl, R. (1956). Mass communication and para-social interaction: Observations on intimacy at a distance. Psychiatry, 19, 215-229.

Juul, J. (2009). A casual revolution: Reinventing video games and their players. The MIT Press.

Kent, E. (2020). Animal Crossing's Nook Miles Tickets have become a bizarre trading currency. Eurogamer. https:/www.eurogamer.net/articles/2020-04-22-animal crossings nook-miles-tickets-have-become-a-bizarre-trading-currency

Kim, J. (2014). Interactivity, user-generated content and video game: An ethnographic study of Animal Crossing: Wild World. Continuum, 28(3), 357-370.

Knapp, M. L., Hart, R. P., Friedrich, G. W., \& Shulman, G. M. (1973). The rhetoric of goodbye: Verbal and nonverbal correlates of human leave taking. Speech Monographs, 40(3), 182 198. 
71 Loading... The Journal of the Canadian Game Studies Association

Vol 13(22): 59-71

http://loading.gamestudies.ca

Lazzaro, N. (2009). Why we play: Affect and the fun of games. In A. Sears \& J. A. Jacko (Eds.), Human-Computer Interaction: Designing for Diverse Users and Domains (pp. 155-175). CRC Press.

Liffreing, I. (2020). Brands host virtual events in Animal Crossing: game offers plenty of customization tool, but creating an entire branded island can take a surprising amount of time and effort. Advertising Age, 91(12), 6

Mateas, M. (2001). A preliminary poetics for interactive drama and games. Digital Creativity, $12(3), 140-152$.

Murray, J. H. (1997). Hamlet on the holodeck: The future of narrative in cyberspace. New York, NY: The Free Press.

Norman, D. A. (1990). The design of everyday things. New York, NY: Doubleday.

Shishikura, M. (2017). Songs for distance, dancing to be connected: Bonding memories of the Ogasawara Islands. In K. Gillespie, S. Treloyn, \& D. Niles (Eds.), A Distinctive Voice in the Antipodes: Essays in Honour of Stephen A. Wild (pp. 218-250). Acton, Australia: ANU Press.

Wan, Z. (2020). The 5 stages of grief after saying goodbye to an Animal Crossing villager. Twinfinite. https://twinfinite.net/2020/05/stages-grief-saying-goodbye-animal-crossing villager/

Williams, R. (2014). Chapter 3: Structure of feeling and selective tradition. In J. McGuigan (Ed.), Raymond Williams on Culture \& Society: Essential Writings (pp. 27-56). London: SAGE Publications. (Original work published 1961)

\section{Ludography}

Nintendo EPD. (2020). Animal Crossing: New Horizons [Nintendo Switch]. Nintendo. Nintendo EAD. (2012). Animal Crossing: New Leaf [Nintendo 3DS]. Nintendo. 